\title{
LOCALLY CONCENTRATED DAMAGE AT SHIMONIIKAWA COAST, TOYAMA BAY, JAPAN DUE TO GIANT SWELL WAVES
}

\author{
Roshan Suminda Ranasinghe ${ }^{1}$, Yutaro Fukase ${ }^{1}$, Shinji Sato ${ }^{1}$ and Yoshimitsu Tajima ${ }^{1}$
}

\begin{abstract}
This paper summarizes results of the preliminary research work, which was completed on identifying and assessing the details of locally concentrated damage along the Shimoniikawa coast, Toyama Bay, Japan due to high swell waves (Yorimawari waves, in Japanese), which occurred on $24^{\text {th }}$ February 2008. A comprehensive analysis has been performed on water surface elevations converted from the total water pressure data, which were obtained at Tanaka observation point from $14^{\text {th }}$ February $-29^{\text {th }}$ February 2008 to investigate the strength of these waves. The spectrum analysis showed a perceptible development of long wave components during this event, which was generated by the nonlinear (secondary) interactions of free waves. Several other mechanisms were also found to be in existence, which were responsible for the high wave overtopping and damage due to concentration of waves at some sites along the Shimoniikawa coast. Furthermore, numerical simulations have been performed to verify the wave transformation and concentration of waves at damaged sites using a model developed based on Nwogu (1993) Boussinesq-type equations.
\end{abstract}

Keywords: swell waves; spectral density; nonlinear interactions; Boussinesq-type model; wave-current interaction

\section{INTRODUCTION}

Several coasts on the Toyama Bay and Sado Island were severely damaged by the long period giant swell waves called "Yorimawari" waves on $24^{\text {th }}$ February, 2008. These waves were generated by winds due to low pressure regions developed near Hokkaido west sea area and they propagated towards Toyama Bay from Northeast and North-Northeast directions. The ongoing project focuses on investigating the localized damage due to wave concentration in Ashizaki, Shimoniikawa coast during this extreme event. However, Ashizaki coast is not the only site, which had experienced severe wave overtopping and damage during this high swell wave attack. There had been a serious damage to Fushiki and Toyama ports also (southern part of Toyama Bay) at several locations due to the direct invasion of Yorimawari waves into the Toyama Bay.

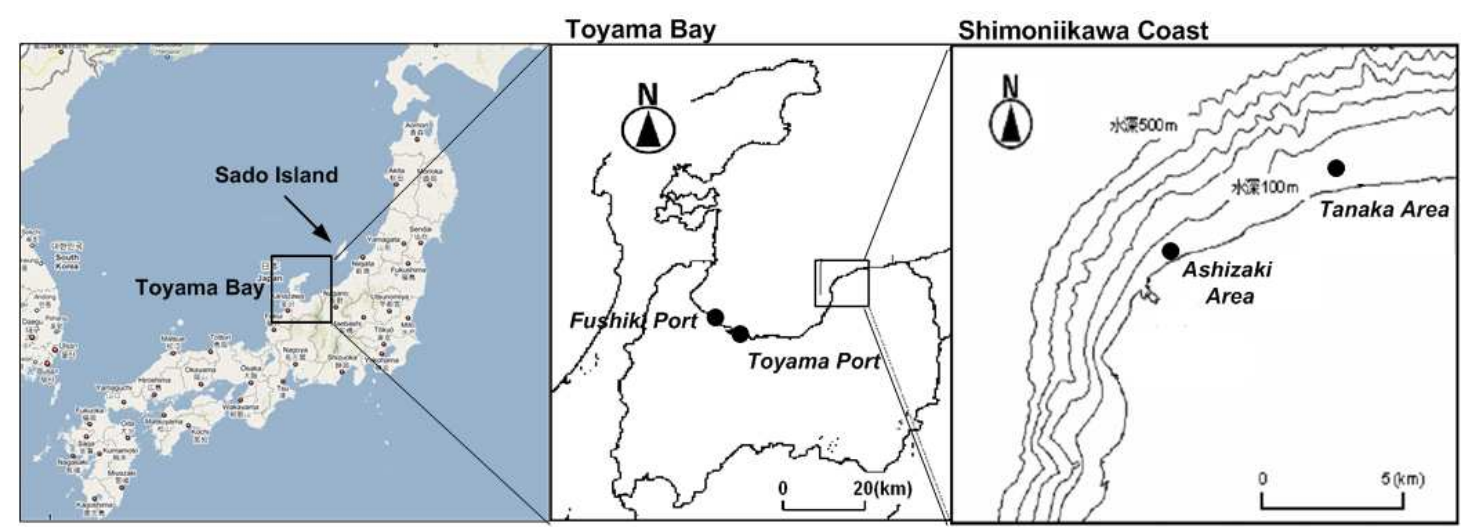

Figure 1. Geographical location of Shimoniikawa coast, Toyama Bay, Japan.

According to the reports, which were published earlier, the significant wave height and period were $4.42 \mathrm{~m}$ and $14.2 \mathrm{~s}$ at Fushiki observation point (water depth of $46.4 \mathrm{~m}$ ) respectively, whereas they were as high as $9.92 \mathrm{~m}$ and $16.2 \mathrm{~s}$ respectively at Toyama observation point (water depth of $46.4 \mathrm{~m}$ ) during this event.

Figure 2 shows a snapshot over Ashizaki area. During the swell wave attack, high wave overtopping was observed and the overtopped waves were found to be running up to a long distance inland from the seawalls. As mentioned above, Ashizaki is the mostly damaged site and the final objective of this project is to propose appropriate countermeasures against such damage in this area. The preliminary work of this project includes, identifying and investigating the mechanism of

\footnotetext{
${ }^{1}$ Department of Civil Engineering, The University of Tokyo, 7-3-1, Hongo, Bunkyo-ku, Tokyo, 113-8656, Japan.
} 
concentration of waves along the Shimoniikawa coast, using observation data analysis, small-scale laboratory experiments and numerical simulations.

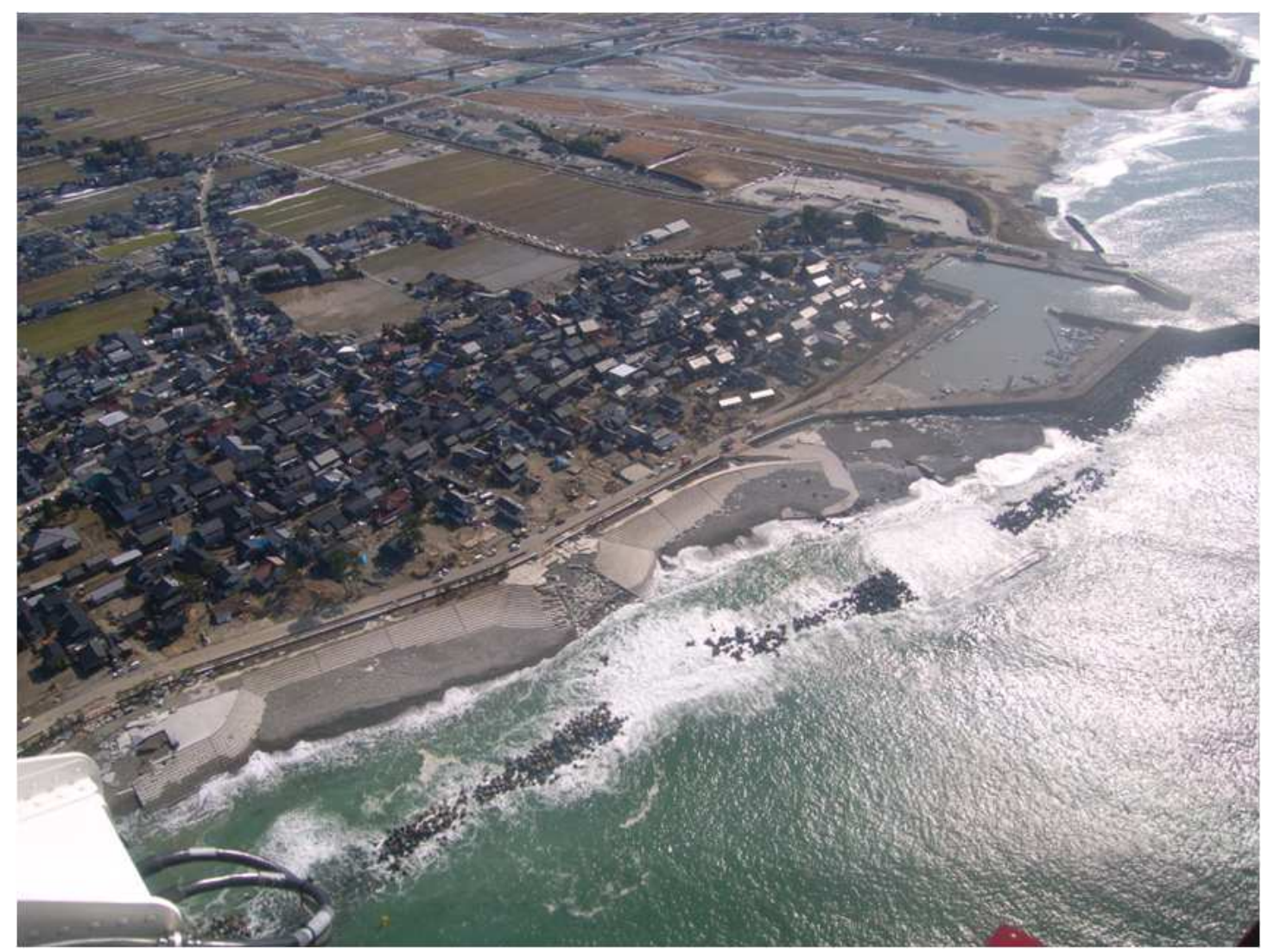

Figure 2. Snapshot over Ashizaki area.

\section{NUMERICAL MODEL}

\section{Governing equations}

Numerical simulations were performed to verify the wave transformation in Tanaka area and mechanism of wave concentration in Ashizaki area using a model developed based on Nwogu (1993) Boussinesq-type equations.

Continuity equation;

$$
\eta_{t}+\nabla \cdot\left[(h+\eta) \mathbf{u}_{\alpha}\right]+\nabla \cdot\left\{\left(\frac{z_{a}^{2}}{2}-\frac{h^{2}}{6}\right) h \nabla\left(\nabla \cdot \mathbf{u}_{\alpha}\right)+\left(z_{\alpha}+\frac{h}{2}\right) h \nabla\left[\nabla \cdot\left(h \mathbf{u}_{\alpha}\right)\right]\right\}=0
$$

Momentum conservation equation;

$$
\mathbf{u}_{a t}+g \nabla \eta+\left(\mathbf{u}_{\alpha} \cdot \nabla\right) \mathbf{u}_{a}+\left\{z_{\alpha} \nabla\left[\nabla \cdot\left(h \mathbf{u}_{a t}\right)\right]+\frac{z_{a}^{2}}{2} \nabla\left(\nabla \cdot \mathbf{u}_{a t}\right)\right\}+\mathbf{F}_{f r}-\mathbf{R}_{b r}=0
$$

Two additional terms have been introduced into momentum conservation equation to simulate energy dissipation due to wave breaking and bottom friction. A simple eddy viscosity-type of formulation is used to simulate the energy dissipation due to wave breaking, following Kennedy et al. (2000) and the rate of energy dissipation is expected to be governed by the magnitude of eddy viscosity, which is related to turbulent kinetic energy (computed using transport equation, Eq. 3) and turbulent length scale (Nwogu and Demirbilek, 2001). The parameter $B$ is introduced to ensure that turbulence is produced only when horizontal velocity at a reference water depth, $u_{\alpha}$, exceeds a threshold velocity. The length scale, $l_{t}$ is set to be of the order of incident wave height, while the empirical coefficient, $C_{D}$, is set to be 0.02 . 


$$
k_{t}+\mathbf{u}_{s} \cdot \nabla k=\sigma \nabla \cdot \nabla\left(v_{t} k\right)+B \frac{l_{t}^{2}}{\sqrt{C_{D}}}\left[\left(\frac{\partial u}{\partial z}\right)^{2}+\left(\frac{\partial v}{\partial z}\right)^{2}\right]_{z=\eta}^{3 / 2}-C_{D} \frac{k^{3 / 2}}{l_{t}}
$$

For computation of wave run-up, an improved slot technique (Kennedy et al., 2000) was utilized.

\section{RESULTS AND DISCUSSION}

Shimoniikawa coast has very unique nearshore bathymetry, which consists of abruptly changing bottom slopes in alongshore direction in tandem. There exists a prominent alongshore variation of bottom slope in Ashizaki area particularly, where the severest damage during the swell wave invasion was observed. The average bottom slope over the mildly sloping bed, seaward from the damaged site is around 1:40, whereas that over the region just south of damaged site is as steep as 1:4 (see Figure 3).

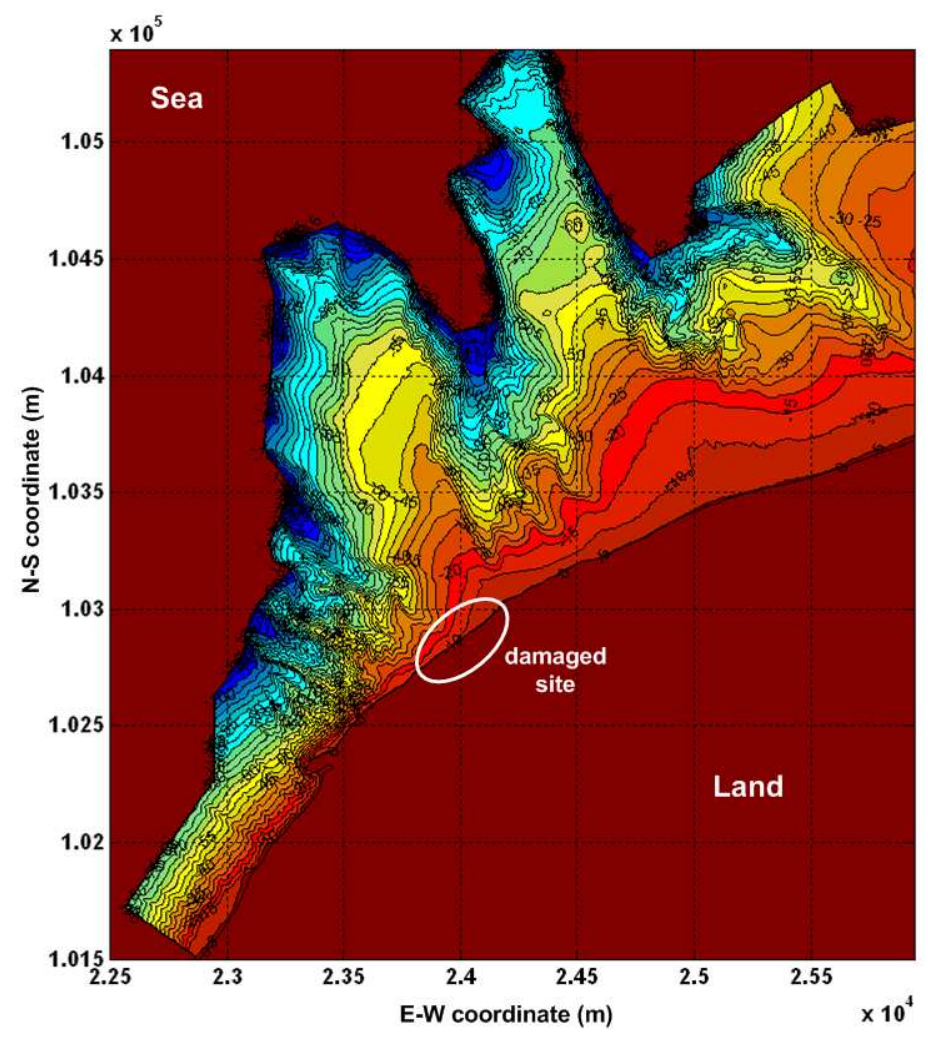

Figure 3. Nearshore bottom topography in Ashizaki area.

A couple of mechanisms were found to be in existence, which lead to wave concentration at the damaged site in Ashizaki area. The presence of long mildly sloping convex bathymetry seaward from the damaged site makes the incoming wave energy to be converged by refraction. It is almost certain that the concentrated short waves would eventually be broken and dissipate the energy as they approach the coast. However, if there exist any low frequency fluctuations in the water levels, they may reach the shore with no breaking. Such mechanism is expected to amplify the wave heights locally. Tajima et al. (2009) reported such experience of local concentration of waves along the Seisho coast, Japan during Typhoon T0709.

Small-scale laboratory experiments and simulations were conducted previously (Ranasinghe et al., 2010) to verify the mechanism of wave concentration over abruptly changing bottom topography in alongshore direction, which primarily results due to wave-current interaction (will not be explained in detail in this paper).

\section{Spectrum analysis}

To investigate the growth of low frequency fluctuations during the swell wave attack, the total pressure data obtained at the Tanaka observation point (Figure 1) were analyzed (no data could be obtained at the damaged site). The total pressure data at nearbottom (-12.8m from water level) were 
available from $14^{\text {th }}$ February $-29^{\text {th }}$ February 2008 , which were sampled at $2 \mathrm{~Hz}$. These pressure data were then transformed to obtain the free water surface fluctuations and the analysis has been carried out in 20 minutes segments.

Figure 4 shows the temporal variation of total pressure (blue line) measured near the seabed from 8.10 a.m -8.30 a.m. on $24^{\text {th }}$ February (Yorimawari waves hit the Shimoniikawa coast with it's maximum strength during this period). Red line represents the mean pressure during this 20 minute segment.

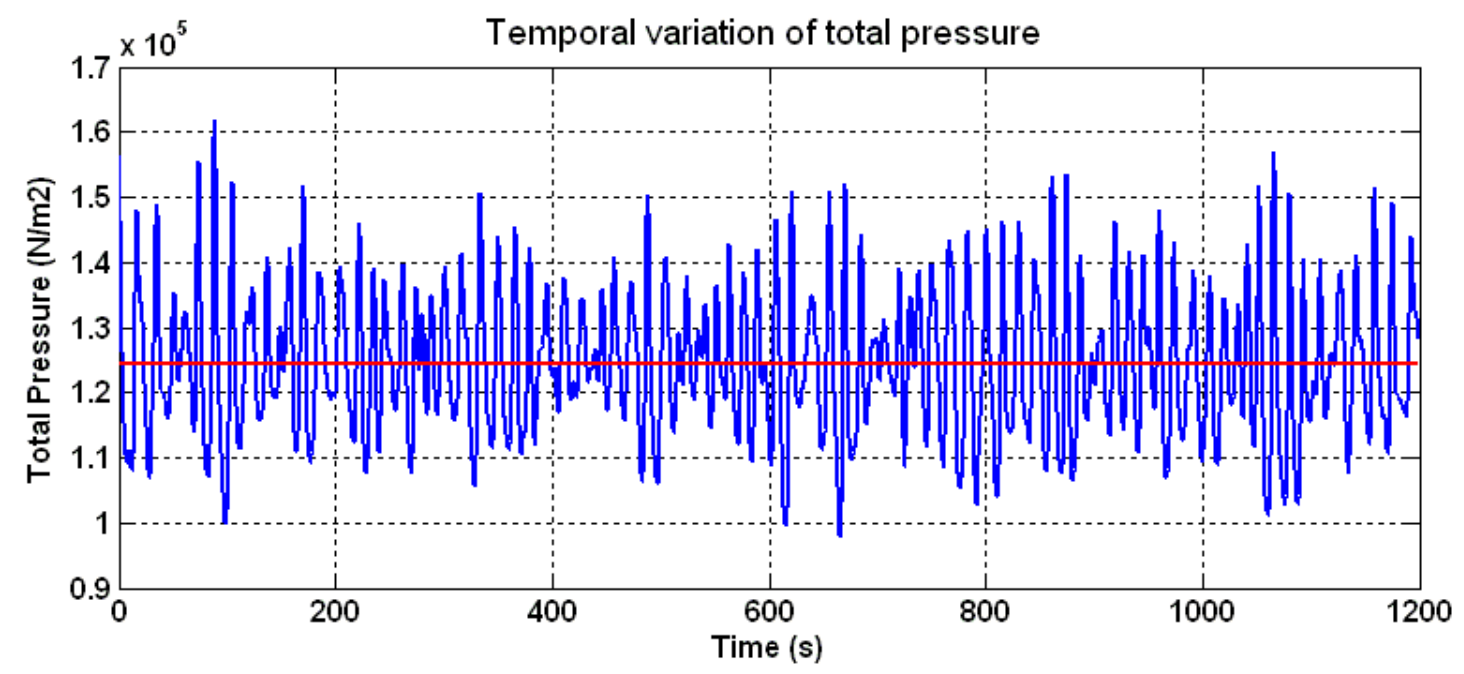

Figure 4. Temporal variation of total pressure from 8.10 a.m -8.30 a.m. on $24^{\text {th }}$ February 2008 .

According linear wave theory, the total pressure under wave action at any water depth reads as:

$$
P=-\rho g z+\rho g \eta \frac{\cosh k(h+z)}{\cosh k h}
$$

Then the dynamic pressure head at sea bottom $(z=-h)$ is given by:

$$
\eta_{P}=\left(\frac{P}{\rho g}-h\right)=\eta \frac{1}{\cosh k h}
$$
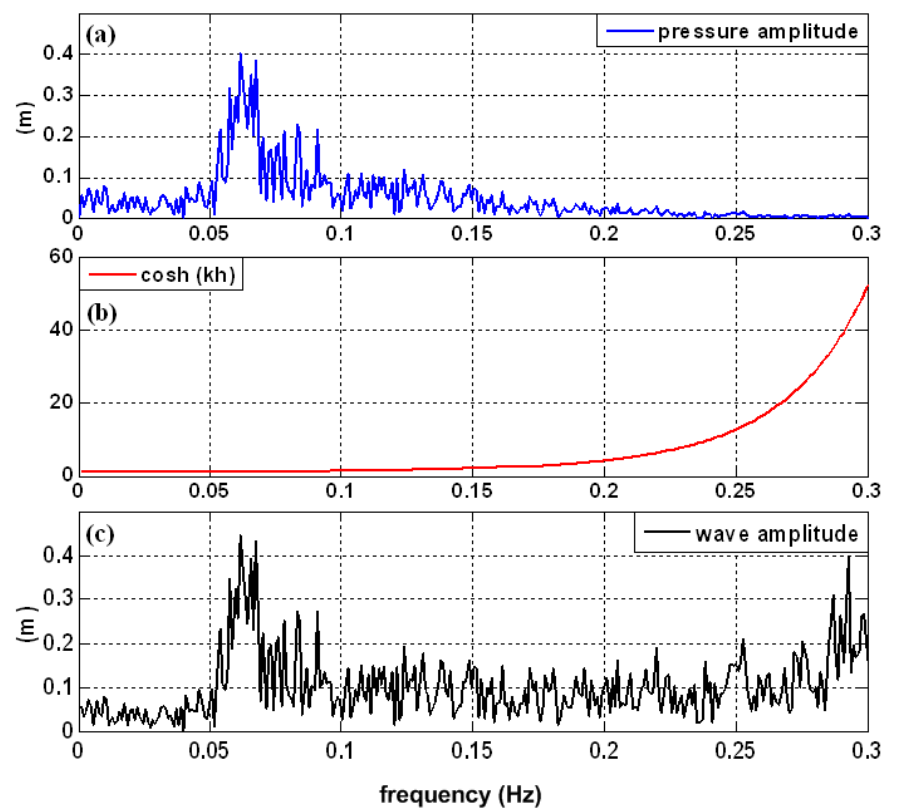

Figure 5. Distribution of pressure head and wave amplitude over frequency range. 
which yields to a direct relationship between free water surface fluctuations $(\eta)$ and dynamic pressure head $\left(\eta_{p}\right)$. The time series of dynamic pressure was decomposed to obtain the pressure head amplitude at different frequencies using Fourier transformation. As it could be easily observed from Figure 5, to avoid any unnecessary overestimation of the spectra, the region, $\cosh k h=3\left(\log _{10} f>-0.75\right)$ was ignored.
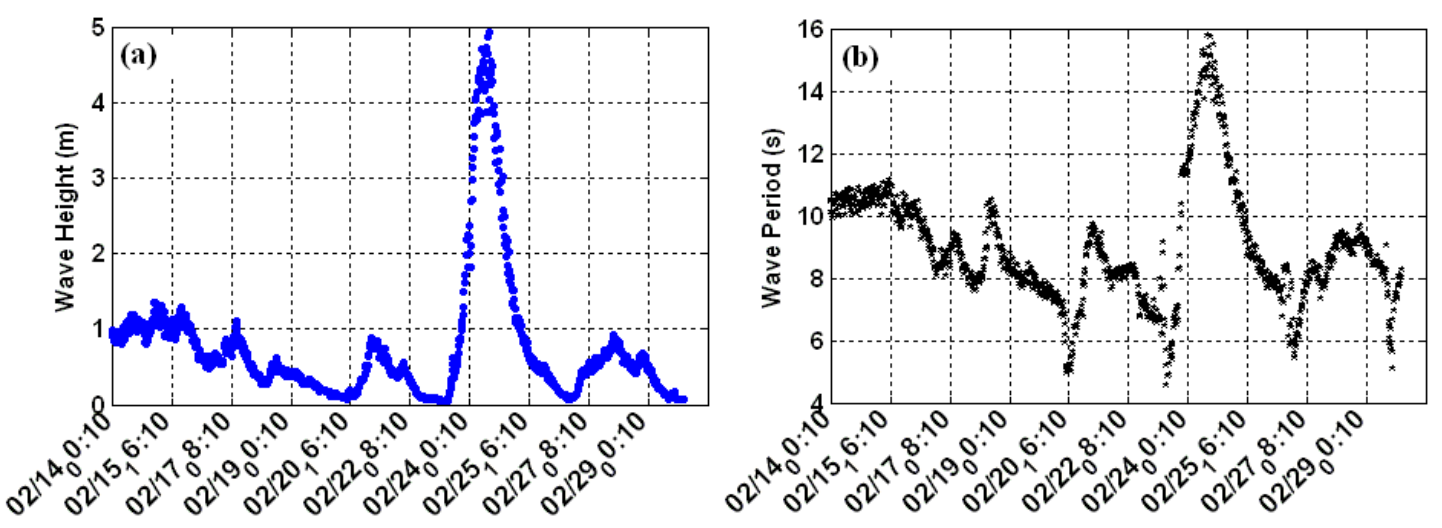

Figure 6. Temporal variation of significant wave height and wave period over 16 days period.

By back calculation, the free water surface fluctuations were obtained and the significant wave height and wave period were computed by using zero-down cross method for each 20 minute segment. Figure 6 shows the temporal variation of significant wave height and wave period over 16 days, which were computed for each 20 minute segment. According to these figures, clearly the maximum significant wave height on $24^{\text {th }}$ February is almost 5-10 times larger than the significant wave height observed on an average day, whereas the maximum significant wave period on $24^{\text {th }}$ is $1.5-2.0$ times larger than the significant wave period observed on an average day.

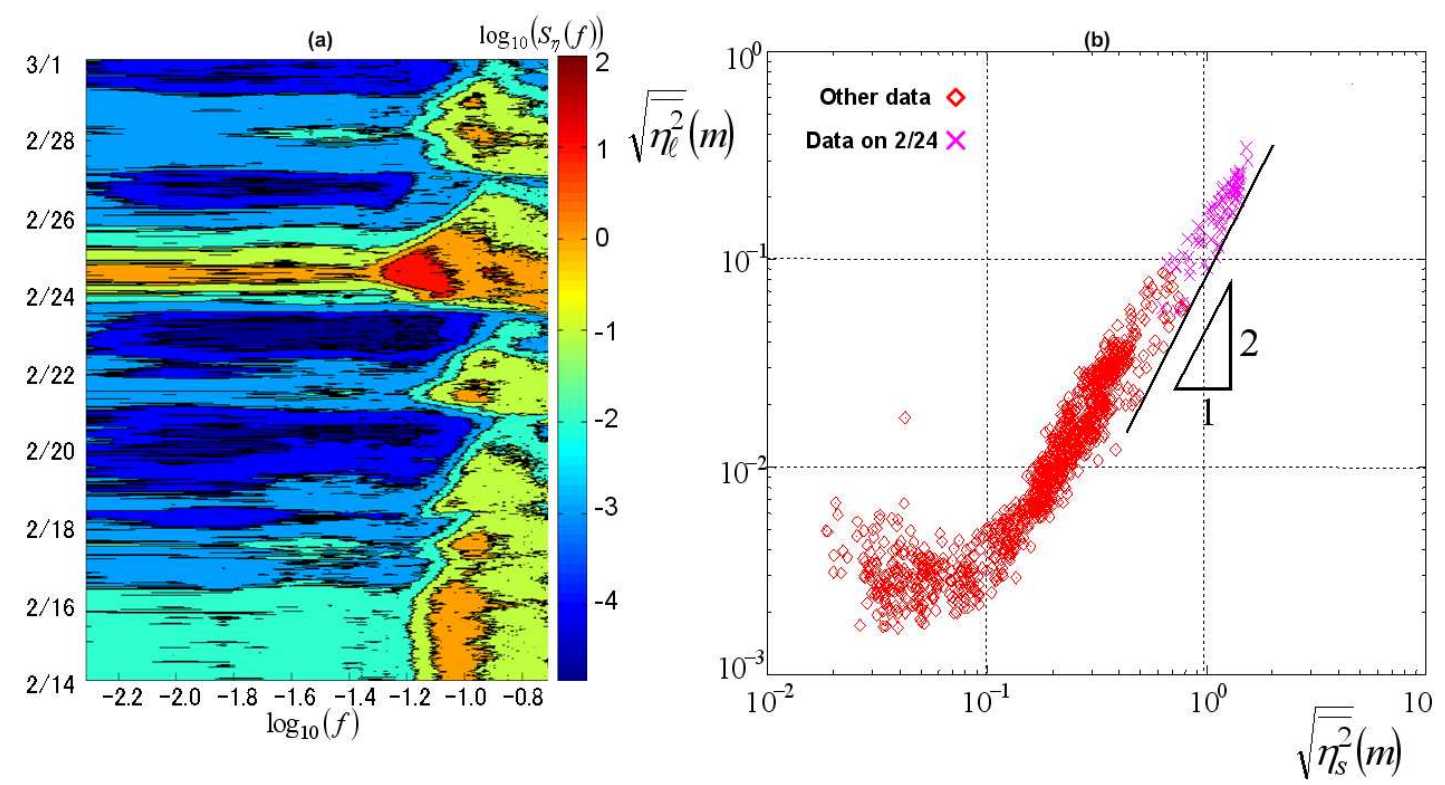

Figure 7. Spectral density distribution (a) and $\sqrt{\overline{\eta_{l}^{2}}}$ of long waves vs. $\sqrt{\overline{\eta_{s}^{2}}}$ of short waves (b) over 16 days period.

The spectral densities are computed using the wave amplitudes, which are calculated (Figure 5) and are shown in Figure 7(a). A perceptible difference is observed of the spectral density in the morning of $24^{\text {th }}$ February, when high swell waves invaded the Toyama bay. Obviously compared to the other days, the spectrum is quite high on $24^{\text {th }}$ and the maximum spectrum corresponds to $f \approx 0.067 \mathrm{~Hz}$. There is a clear development and growth of long wave components during this day, which 
predominantly originate from 'difference interactions' of free waves. Moreover, the double frequency waves, which originate from 'sum interactions' also seem to be significant.

Due to this perceptible growth of long waves on $24^{\text {th }}$, a comparison was made between long wave energy vs. short wave energy and is presented in Figure 7(b). In the separation, we assumed the waves, which are having a frequency lower than 0.04 to be long waves and waves, which are having a frequency larger than 0.04 to be short (this includes both short and swell waves). The pink crosses in Figure 7(b) depict the data on $24^{\text {th }}$ February, whereas the red diamonds depict the data on remaining days. The interesting feature here is the nonlinear growth of long wave energy levels compared to short wave energy levels during the swell wave attack. This is found to be one of major reasons and mechanisms of amplification of water levels during this extreme event.
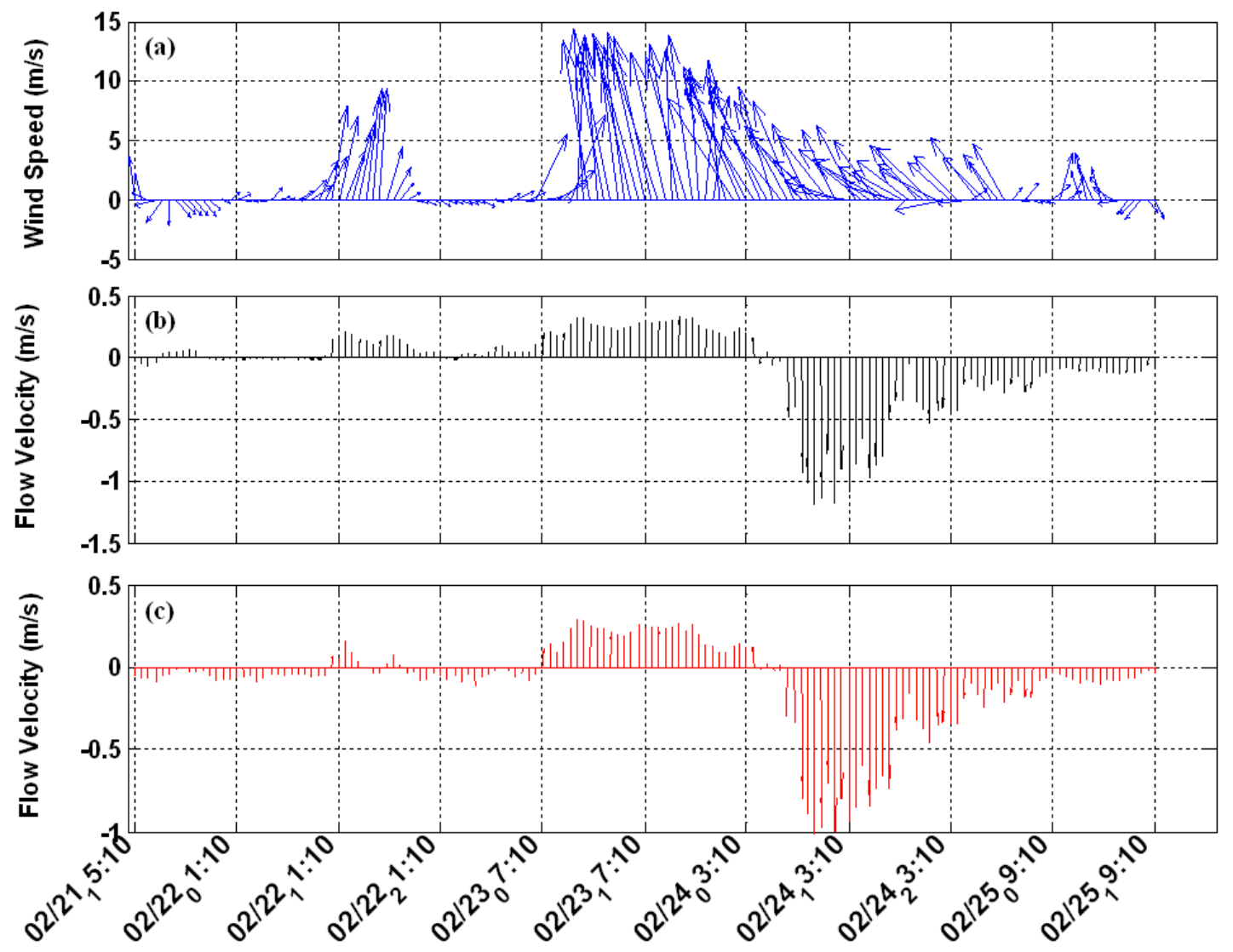

Figure 8. Average wind velocity (a), flow velocity at $5.8 \mathrm{~m}$ from water level (b) and flow velocity at $12.8 \mathrm{~m}$ from water level over 5 days period at Tanaka observation point.

The details of wind and flow velocities recorded at Tanaka observation point from $21^{\text {st }}$ February $-25^{\text {th }}$ February 2008 (over 5 days period) are depicted in Figure 8. Local wind (Figure 8(a)) attained its maximum speed (nearly $15 \mathrm{~m} / \mathrm{s}$ ) on $23^{\text {rd }}$ February (i.e. day before the arrival of high swell waves) and the direction had been from west to east. Before the arrival of Yorimawari waves a clear correlation can be observed between local wind vectors and flow vectors (both in magnitude and direction), which confirmed the local flow is due to wind driven current. The current velocity is about $2 \%$ of the wind velocity on average. During the Yorimawari wave attack, the flow at mid layer and bottom layer grew up to a maximum velocity of about $1-1.2 \mathrm{~m} / \mathrm{s}$, which is relatively high and interestingly the direction of the flow changed to east to westward current. No correlation can be found between wind field and flow field during the high swell wave attack and this flow is confirmed to be due to wave breaking induced currents. 


\section{Numerical Modeling}

Numerical simulations were conducted to confirm the wave transformation in Tanaka area and wave concentration mechanism (s) in Ashizaki area using both monochromatic and group waves. Numerical simulations conducted with monochromatic waves and group waves trains, were set to have same energy levels at the offshore incident boundary (the r.m.s. of incident wave heights is set to be the same). The monochromatic waves were generated with an incident wave height of 5.6mand a wave period of 14.0s, whereas group waves were generated with the wave theory proposed by Tick (1959), which incorporates secondary nonlinear interactions. These group wave trains included primary bichromatic wave trains having amplitude of $4.0 \mathrm{~m}$ each and wave periods of $12.6 \mathrm{~s}$ and $15.4 \mathrm{~s}$ respectively.

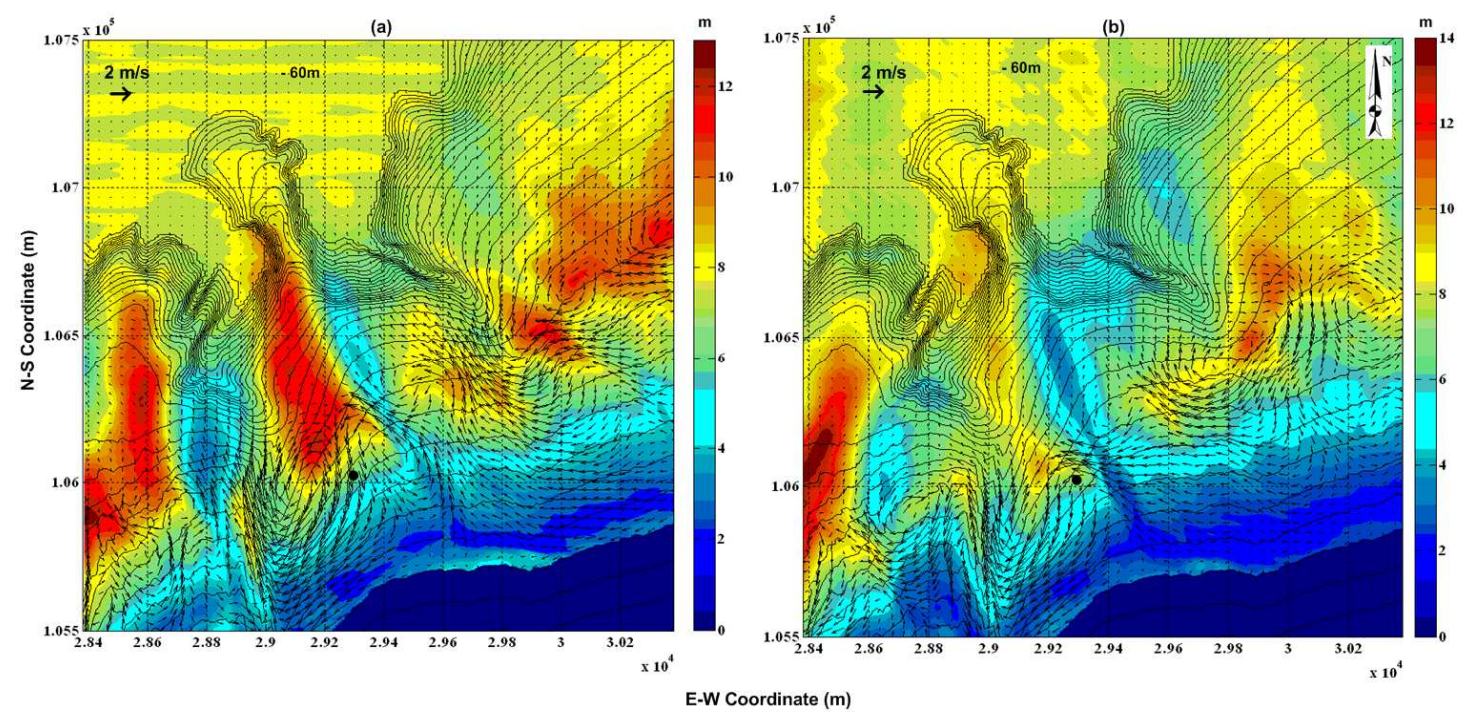

Figure 9. Nearshore wave (maximum) and current field in Tanaka area under group waves approaching from North (a) and 15 degrees from North to East (b).

To be compatible with the frequency dispersion characteristics of Nwogu (1993) Boussinesq-type equations, the offshore water depths were rendered at $60 \mathrm{~m}$ depth contour in all numerical simulations. The nearshore wave (maximum wave height) and depth averaged current field computed for Tanaka area under group waves with waves approaching from North are shown in Figure 9(a). Though there is some consistency between the observed maximum wave height and computed maximum wave height at Tanaka observation point (black dot), the computed depth averaged current velocity deviated from the actual both in magnitude and in direction.

Figure 9(b) shows the nearshore wave (maximum wave height) and depth averaged current field computed for Tanaka area under group waves with waves approaching 15 degrees from North to East at the incident boundary. This incident angle is set considering the deepwater wave angle (wave angle in deepwater is assumed to be from N-NE) and offshore water depth of $60 \mathrm{~m}$. In this simulation, the direction of the depth averaged current velocity is changed from North-South to East-West, which is far more consistent with the observed direction of the current velocity during the Yorimawari wave attack.

The next set of simulations was carried out for Ashizaki area to investigate the wave concentration mechanism and in these simulations; the onshore boundary was set to be perfectly reflective. This was found to be more realistic to the actual conditions at Ashizaki coast with steep sea walls. Similar to the simulations in Tanaka area, the offshore water depth was rendered at $60 \mathrm{~m}$ depth contour. The nearshore wave and current field in Ashizaki area under monochromatic waves approaching from north are depicted in Figure 10 and the maximum and minimum water levels recorded along the sea wall are shown in lower figure. The location of maximum water level obtained from the computations was consistent with the location, which experienced severe wave overtopping. The wave overtopping near 24000, E-W coordinate was mainly due to the wave concentration over long mildly sloping convex bathymetry. No damage had been reported along the boundary eastward of this area, as the waves are found to dissipate a lot of energy after breaking over the mildly sloping topography. 


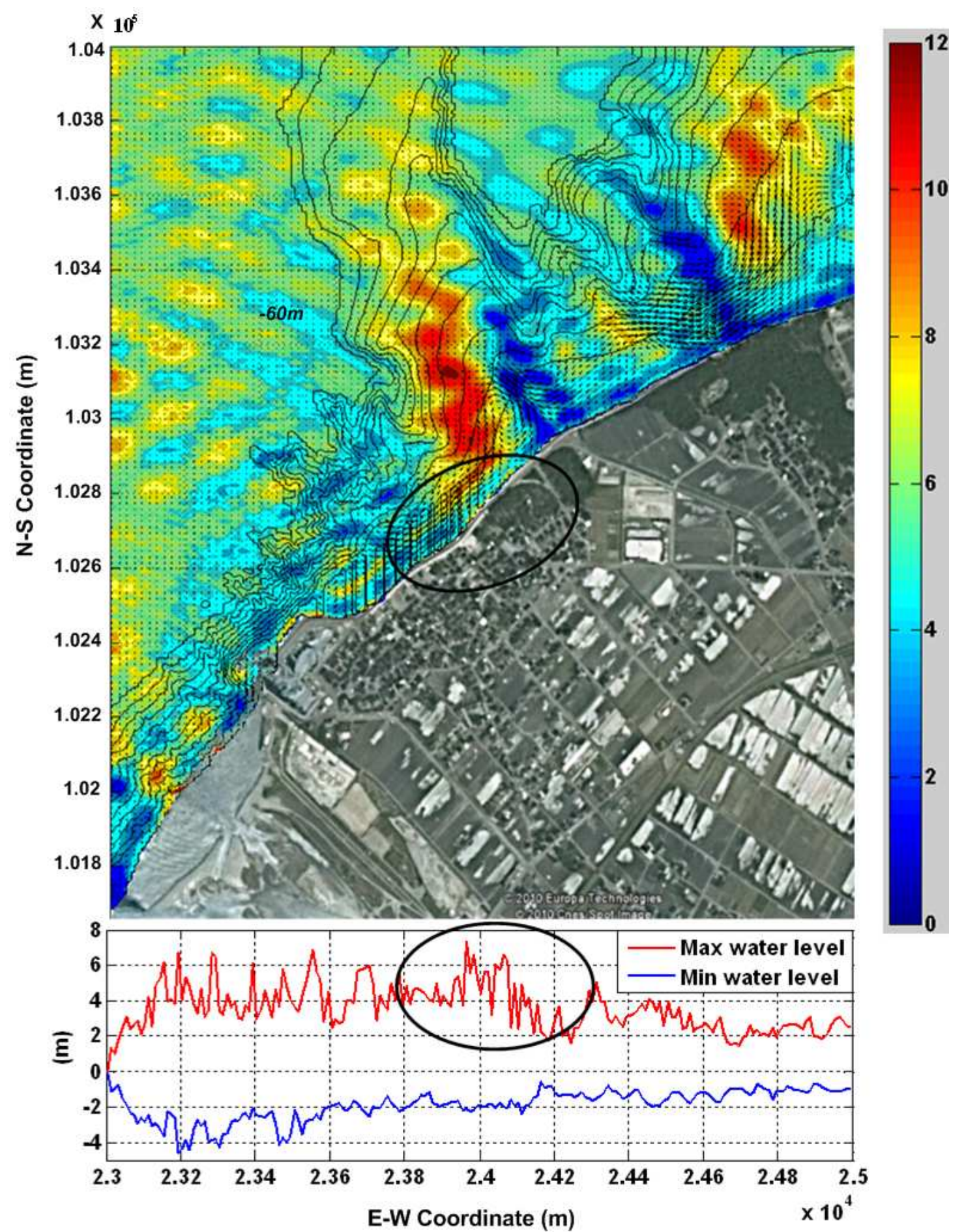

Figure 10. Nearshore wave and current field in Ashizaki area under monochromatic waves approaching from north.

Development of high wave radiation stress by local wave concentration, results relatively strong alongshore current, which is further enhanced by the oblique incidence of waves. As it is illustrated in Figure 11, the average depth-averaged current is found to be around $2 \mathrm{~m} / \mathrm{s}$, which is high enough to cause wave-current interaction. However, a detailed analysis had not been performed to clarify the significance of wave-current interaction on wave convergence near the damaged zone.

On the other hand the high water level observed along the boundary westward of the mostly damaged zone is found to be due to the less dissipation of wave energy. 


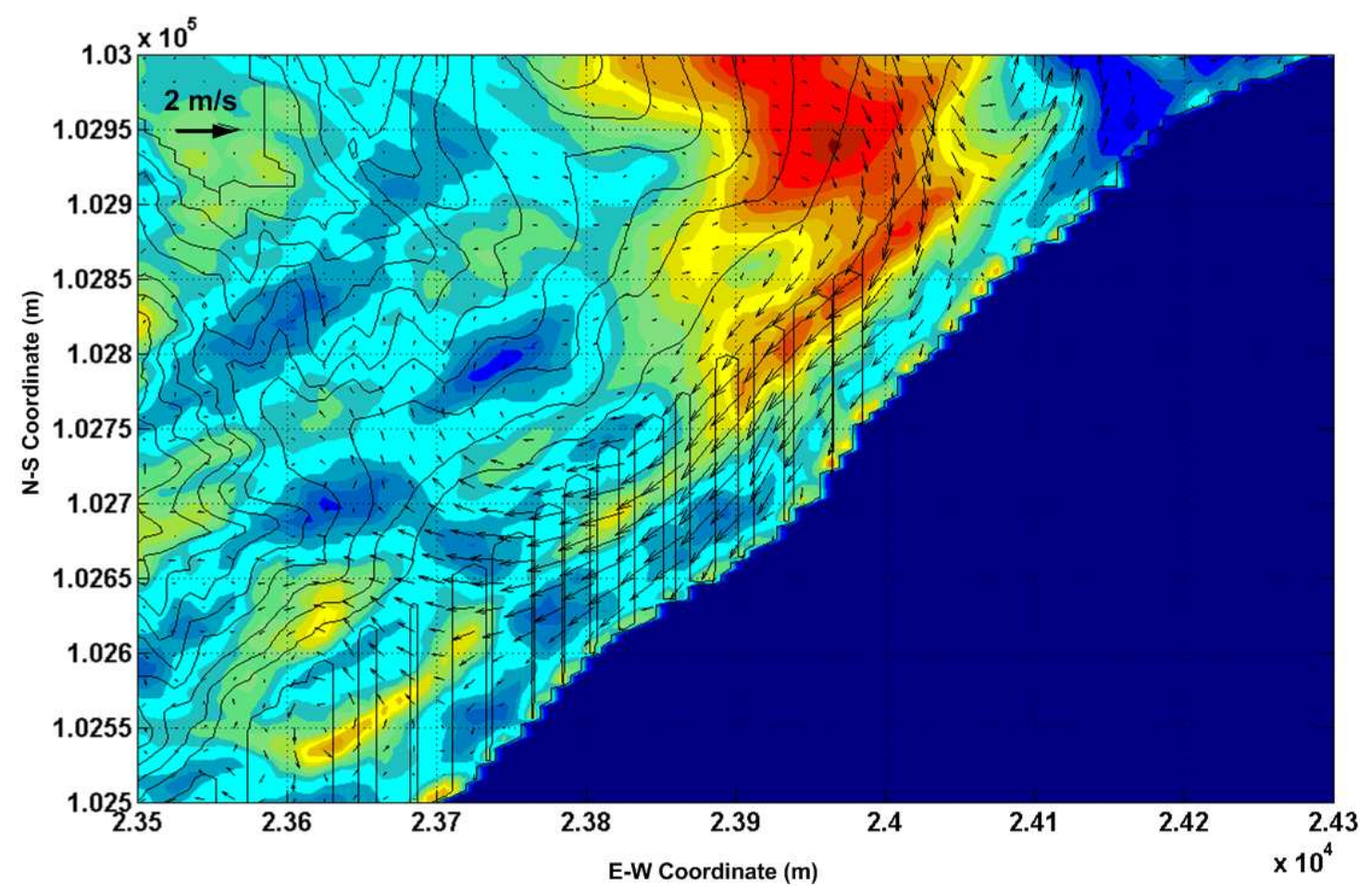

Figure 11. Nearshore wave and current field near mostly damaged zone of Ashizaki area under monochromatic waves approaching from north.

\section{CONCLUSIONS}

A comprehensive study has been performed to investigate the mechanism of locally concentrated damage along the Shimoniikawa coast by high swell waves, which occurred on $24^{\text {th }}$ February 2008. The spectrum analysis completed on the water level fluctuations at Tanaka observation point showed perceptible development of long wave components (due to nonlinear interactions) during this extreme event, which is fund to be one of the main reasons of high overtopping along the damaged zone.

Numerical simulations and small-scale physical model tests were conducted to verify the mechanism(s) of local concentration of waves. The refraction of waves over the long mildly sloping convex bathymetry is found to be the main reason for the convergence of wave energy in Ashizaki area. Though small-scale laboratory experiments showed possible influence of wave-current interaction on local concentration of wave energy, this mechanism is yet to be verified with detailed numerical simulations and large scale laboratory experiments with actual bathymetry.

\section{ACKNOWLEDGMENTS}

This project is being financed by the Japan Railway Construction, Transport and Technology (JRTT) Agency and their support is greatly appreciated.

\section{REFERENCES}

Hamada, T. [1964] "Secondary interactions of surface waves," in Proc. Coastal Engineering, JSCE, 12(1) $12-18$.

Ishii, T., Isobe, M., Watanabe, A. [1994] "Improved boundary conditions to a time-dependent mild slope equation for random waves," in Proc. $24^{\text {th }}$ Int. Conf. Coastal Engineering, ASCE, pp. 272284.

Kennedy, A.B., Chen, Q., Kirby, J.T., Dalrymple, R.A. [2000] "Boussinesq modeling of wave transformation, breaking and run-up, I:1D," Journal of Waterways, Port, Coastal and Ocean Engineering, ASCE, 126 (1), 39-47.

Nwogu, O.J. [1993] "Alternative form of Boussinesq equations for nearshore wave propagation," Journal of waterways, Port, Coastal and Ocean Engineering, ASCE, 119 (6), 618-638. 
Nwogu, O.J. [1996] "Numerical prediction of breaking waves and currents with Boussinesq model," in Proc. $25^{\text {th }}$ Int. Conf. Coastal Engineering, ASCE, pp. 31-45.

Ranasinghe, R. S. [2009] "Modelling waves and currents around submerged breakwaters and over complex bathymetries," Doctoral thesis submitted to Department of Civil Eng, The University of Tokyo.

Ranasinghe, R.S., Fukase, Y., Sato, S., Tajima, Y. [2010] "Local concentration of waves due to abrupt alongshore variation of nearshore bathymetry," Coastal Engineering Journal (under review).

Tajima, Y., Sato, S. [2009] "Numerical investigations of locally concentrated damages on Seisho coast due to Typhoon T0709," in Proc. $5^{\text {th }}$ Int. Conf. on Asian and Pacific Coasts, pp. 164-170.

Tick, L.J. [1959] “A non-linear model of gravity I," Journal of Mathematics and Mechanics, 8(5), 643652.

Nwogu, O.J., Demirbilek, Z. [2001] "BOUSS-2D: A Boussinesq wave model for coastal regions and harbours," ERDC/CHL TR-01-25. 